The Korean Economic Review

Volume 28, Number 2, Winter 2012, 117-136.

\title{
Migrants, Ethnicity and the Welfare State
}

\author{
Gil S. Epstein*
}

\begin{abstract}
A model is set up where migrants must choose a level of social traits and consumption of ethnic goods. As the consumption level of ethnic goods increases, the migrants become ever more different to the local population and are less assimilated. Less assimilation affects the reaction of the local population to the migrants and their willingness to accept the newcomers. This social phenomenon and affects wages and unemployment. We show that the growth in the unemployment and social benefits of legal migrants increases the consumption of ethnic goods, thus creating a trap wherein the willingness of the local population to accept the migrants into the economy decreases. This process also increases the probability of the migrants' dependence on the welfare state. On the other hand, illegal migrants could play an important role in the assimilation of the legal migrants.
\end{abstract}

JEL Classification: F22, O15, D6

Keywords: Welfare state, Social benefits, Ethnic goods, Social trait, Assimilation, Unemployment

\section{Introduction}

In this paper we wish to look at the relationship between the welfare state ${ }^{1}$, assimilation and the legal and illegal migrants' participation in the labor market. We consider the relationship between the migrants' consumption of ethnic goods, the willingness of the local population to accept them into the economy and the legality of the migrants' status. This willingness affects the productivity and the wages of both legal and illegal migrants, and thus their employment.

Migrant participation in labor markets is quite complex and, in many ways, different from that of the local population. Studies of migrants around the world

Received: June 12, 2012. Revised: Sept. 12, 2012. Accepted: Sept. 19, 2012.

* Department of Economics, Bar-Ilan University, Ramat Gan 52900, Israel, IZA, Bonn and CReAM London.E-mail: Gil.Epstein@biu.ac.il, Tel: +972 528550 407, Fax: +972 35353180.

${ }^{1}$ In all EU countries, immigrants are less likely to be on old-age and health benefits because they are younger. Therefore, our analysis concentrates on unemployment benefits. 
show, with a few exceptions, that they tend to earn wages substantially lower than those of a comparable local population (see for example Chiswick, 1978 and Borjas, 1990). To a degree, this reflects a failure on the part of the migrants to undertake the effort to assimilate. The "lack of effort" may well be different for the legal and illegal migrants. In general it can arise from a desire to maintain a cultural heritage or separate identity, which would be lost or reduced if the group assimilated. The failure to take active steps to assimilate can also arise in the face of high adjustment costs, such as inadequate language skills, inter-generational or familial conflicts, and ignorance regarding the host country's labor market.

Various indicators are used to measure the degree to which migrants have assimilated. The most common measures, in the economics literature, are wages and earnings, and there is an extremely large literature which examines the rate and degree of decline in wage and earning differences among various groups. Other indicators include labor force participation, poverty, and education, which is now more frequently examined over several generations. Moreover, for immigrants and their descendants, as the length of time in the host country increases, and assimilation occurs, immigrant earningstend to approach those of the comparable local workers. On occasion, migrants out-perform those workers. Recently Constant, Gataullina and Zimmermann (2009) presented the ethnosizer, which measures the ethnic identify of a migrant rather than his ethnicity, using information such as language, culture, societal interaction, history of migration, and ethnic selfidentification. Using the GSOEP 2002 data, it becomes that. Alternative: ethnic identity is more persistent in such specific groups as females, Muslims, and older migrants than in such cultural/religious groups as Catholics or other Christians who assimilate more easily.

Assimilation of migrants in the local culture ${ }^{2}$ is a function of three main elements: 1 . The legality status of the migrant - legal or illegal. 2. The extent to which the migrants wish to assimilate, the effort they invest in maintaining their difference from the local population or holding on to their heritage, and the consumption of ethnic goods, which distinguishes them from the local population (this may well differ depending on the migrant's status). 3. The degree to which the local population welcomes the migrants. Often the local population is less than welcoming, blaming the migrants for depressing wages and displacing local workers - i.e., causing unemployment of the local population. ${ }^{3}$ This presumption has very strong political implications, and is implicit in the calls for increased regulations for immigration, which are heard worldwide. Yet, there is mixed evidence on the migrants' impact on the local workers' majority wages and employment. The migrants' influence depends on whether they are substitutes or complements To the

\footnotetext{
${ }^{2}$ On migration and culture see Epstein and Gang (2010).

${ }^{3}$ On assimilation and international trade see Epstein and Gang (2006).
} 
local workers (Gang and Rivera-Batiz 1994). This perception of the local population exists whether migrants actually lower wages and increase unemployment or not, but, the local workers may take active steps to discourage the migrants from assimilating - through discrimination, isolation, and so on. ${ }^{4}$

Local workers and migrants differ in many ways. One dimension, which distinguishes between the local population and the migrants, is the consumption of specific ethnic goods: the choices of ethnic and religious traits are determined by the consumption of these items. Social customs and the consumptions of ethnic goods take many forms. The simplest type to consider is religion. In all religions individuals have to choose how intensely they wish to keep the laws of their religion. For example, in Islam it could be praying five times a day, going to Mecca once a year, maintaining their dress code, not eating certain food, like pork etc. A Greek immigrant to the USA has to decide if he will keep all the Greek traditions, and whether he will speak Greek at home or send his kids to Sunday Greek school etc.? The level of consumption of ethnic goods may differ from individual to individual. This choice will have an effect on the way the local population accepts the migrants. The level of consumption of ethnic goods may be affected (in equilibrium) by the legal status of the migrants.

The question of assimilation and integration into the labor market of the host co untry has been analyzed in the literature (see for example, Boeri, Hansen and McC ormick, 2002, Bauer, Lofstroem and Zimmermann, 2000 and Venturini, 2004). Acc ording to the standard economic models in this field, the degree of assimilation is in fluenced by individual factors, the characteristics of the home and host countries, th e migration motive, and the expected migration duration. The greater the similarity between the sending and the receiving countries, i.e. the type of ethnic goods each c ountry consumes, the more rapid is the assimilation. ${ }^{56}$

Migrants have to choose their actual level of social traits. Choosing a person's traits has a cost. For example, going every Sunday to church, praying a few times a day, not working on the Sabbath, not eating specific type of foods or at certain places, wearing specific clothes etc., all have opportunity costs. On the other hand, there are benefits from keeping their ideal (satiation) social traits, and any deviation also has a cost. Bisin and Verdier (2000) developed an economic framework, which studied a similar type of evolution about the persistence of ethnic and religious traits

\footnotetext{
${ }^{4}$ The 1997 Euro Barometer survey contained a question on racism. Nearly 33 percent of those interviewed openly described themselves as "quite racist" or "very racist".

${ }^{5}$ On the concept of ethnic human capital, Chiswick (2009) shows that economic determinants of 'successful' and 'disadvantaged' group outcomes are sensitive to the relationship between ethnic and general human capital, especially with regard to externalities in the processes by which they are formed. Policies that welcome ethnic diversity within the larger society without encouraging separation would be desirable. A genuinely inclusive policy of multiculturalism would also be beneficial.

${ }^{6}$ Ethnic groups migrate to similar places and form networks, see for example Bauer et al (2009) and Epstein (2010).
} 
and the role of marriage in the development of the cultural traits of children. In contrast to Bisin and Verdier (2000), we look at how the wage structure and unemployment benefits are affected by the choice of the migrants. Looking at a specific group, Berman (2000) considers the case of the Israeli Ultra-Orthodox men, who study full-time in yeshiva till the age of 40 on average. The paper looks at the question of why fathers, with families living in poverty, choose yeshiva over work. Berman (2000) shows that Yeshiva attendance signals commitment to the community, which provides mutual insurance to members. Our paper differs from this approach since we do not consider the specific type of economy where devotion creates a signal to the community and provides benefits to the individual from such devotion.

The growth perspectives of European Union member countries are seen to be crucially related to the challenge of mobilizing people to work. One issue is that non-economic migrants have more difficulties in economic performance and labor market integration, and provide a larger potential burden to the social security systems than do economic migrants. Recent work in Denmark and Germany (see Tranaes and Zimmermann, 2004, Schultz-Nielsen and Constant, 2004, Constant and Zimmermann, 2005 and Constant, Gataullina and Zimmermann, 2009) has provided new evidence, which indicates that an ever-rising quota of immigrants is unavailable to the labor force. Instead, migrants arrive as refugees, asylum seekers or for family reunification purposes. Differences in labor market attachment might be due to differences in individual characteristics across and within ethnicities, as we claim in this paper.

Epstein (2009) presented a model whereby migrants must choose a level of social traits and consumption of ethnic goods. This framework deals with the relationship between the consumption of ethnic goods, the choice of social traits, wages and the employment of migrants. As the consumption level of ethnic goods increases, the migrants become ever more different from the local population and less assimilated. Epstein (2009) considers the effect that being part, or not being part, of the labor force has on the consumption of ethnic goods, comparing those who are not part of the labor force with the employed and the level of ethnic goods each uses and their chances of assimilation in the host country. In some sense, the model presented in this paper is a more general model that deals with similar issues of employment and the consumption of ethnic goods.

We set up a model where migrants have to choose their level of social traits and consumption of ethnic goods. Each migrant has his/her own ideal (satiation) social traits on the basis of which they choose their consumption level. As the consumption of ethnic goods increases, the migrants become more unlike the local population and are less assimilated. Limited assimilation affects the reaction of the local population to the migrants and their willingness to accept them. This affects wages and unemployment. We show that in unemployment social benefits affect 
the migrant's social chosen traits and their dependency of the welfare state. This effect differs depending on the migrant's legality status. ${ }^{7}$ It is also argued that employed illegal migrants may increase the assimilation process of the legal migrants into the new host country.

\section{The Model}

Each individual (family) has to choose his/her social trait level. This social trait can be seen as ethnic goods consumed by the individual. The migrant's utility, $u$, is a function of four components: (i) the ideal level (the satiation) of the social traits that this individual (family) believes it should aspire to, $I$ (this is also called many times in the literature the bliss point or the satiation point); (ii) the actual level of the social traits the migrant decides to follow, $x^{8}$; (iii) the consumption of other products represented by product $y$; and (iv) the effort invested by the migrant at the workplace, $e$ - those that are unemployed invest zero effort $(e=0)$ and those that work invest a fixed level of $e(>0)$. Below we explain how each of the different variables affects the payoff function of the migrant.

All migrants, legal and illegal, differ in only one dimension, and that is the ideal (satiation) level of social traits they believe they should hold. It is assumed that migrants are distributed uniformly across different levels of the ideal social traits on the interval $[\underline{I}, \bar{I}]: I_{i} \sim U(\underline{I}, \bar{I})$.

Migrant $i$ 's payoff equals to: ${ }^{9} 1011$

$$
u_{i}=-v\left(I_{i}-x_{i}\right)+y_{i}-e_{i}
$$

Let us now look into first component of the utility function: $v\left(I_{i}-x_{i}\right)$, which is the migrant's decrease in utility after choosing an actual level of ethnic goods, level $x$, while his ideal (satiation) level is $I$. The individual's utility decreases if the

\footnotetext{
${ }^{7}$ This may help understanding the phenomena under which immigrants (Germany, Sweden and Denmark) account for approximately 10 percent of the total population and [are recipients of] receiving over 30 percent of the total cash welfare expenditures (Wildasin, 2004).

${ }^{8}$ One could think of $x$ as the level of ethnic identity as measured by the ethnosizer index (see Constant, Gataullina and Zimmermann, 2006).

${ }^{9}$ For example $u_{i}=-\left(I_{i}-x_{i}\right)^{2}+y_{i}-e_{i}$

${ }^{10}$ There exists a disutility from working (Shapiro, and Stiglitz, 1984 and Epstein and Hillman, 2003).

${ }^{11}$ The use of such a utility (loss function) is not new, see Brekke, Kverndokk and Nyborg (2003) and Epstein (2007). Akerlof and Kranton (2000) offer a novel theoretical framework of the utility maximization function by incorporating an individual's self-identification as powerful motivation for behavior. They imply that if individuals achieve their "ideal self" and are comfortable with their identity, then their utility increases, otherwise, it decreases.
} 
individual deviates from his ideal social trait. This deviation can go both ways. Increasing the actual level over the ideal or decreasing the level below the ideal, which will cause the utility to decrease. It is clear that the migrant would prefer to be at his/her ideal position (satiation point); however, this is not always possible. Notice that if the migrant chooses a trait level, which equals his/her ideal, he/she will be at the maximum utility level.

We assume that as the $v(a)$ satisfies:

$$
\frac{\partial v\left(a_{i}\right)}{\partial\left|a_{i}\right|}>0
$$

Namely, deviating from the ideal (satiation/bliss) point, $I_{i}$, decreases the utility. Thus, if we change the actual level $x_{i}$ and get closer to the ideal point, $I_{i}$, then the decrease in the utility, $v_{i}($.$) , will be smaller and thus the utility increases. If we$ increase the actual level beyond (or decrease it below) the ideal point, then the utility will decrease as a result of such a deviation. We have not assumed anything regarding the symmetry of the function $v($.). If the function is symmetric, then a deviation in each direction has the same consequence on the payoff function of the migrant. In other words, increasing the trait or decreasing it by one unit over or below the ideal (satiation/bliss) level, will have the same effect on the migrant's utility. In reality, it may well be that the function is not symmetric, namely, increasing the level of consumption of the ethnic goods decreases the utility by less than the change in the other direction. This, of course, will be a function of the migrants' preferences. If the migrants care about their special social traits, they may prefer to increase their actual traits above the ideal, rather than decrease them.

\section{Budget constraint}

Each migrant can consume two types of products: the social traits, $x$, and all the rest of the products represented by the product $y$. The price of a unit $x$ is denoted by $P_{x}$ while we normalize the price of product $y$ to unity.

Each migrant either legal or illegal, denote the index $s$ to represent the migrants status: $s=n$ for the illegal migrants and $s=l$ for the legal migrants.

Each individual can chose to either work or be unemployed. Unemployed migrants obtain social benefits at a level of $s b(s)(s=n, l)$, and an employed worker obtains an income of $w(s)$. We assume that the earnings from working are always greater than the social benefits obtained by the unemployed: $w(s)>s b(s)$. The income $w$ is a function of the social trait level chosen by the employed worker. There exists a larger literature ${ }^{12}$ which considers the connection between

12 See Constant and Zimmermann, (2005) and Constant, Gataullina and Zimmermann, (2006) on 
assimilation of migrants and their earnings. It has been shown that the more a migrant assimilates, his/her earnings increase, which means that the migrant chooses a low level of social trait (a low level of $x$ ). For a more detailed analysis of the connection between wages, production and ethnicity see the appendix. Therefore, it is assumed that as the level $x$ increases, the wages are at decrease: $\frac{\partial w\left(x_{i}\right)}{\partial x_{i}}<0 .{ }^{13}$ Moreover, the wage of an assimilated migrant is given by $w(0)$.

Denote by $e r_{i}$ the earnings of migrant $i$. Therefore, the budget constraint of migrant $i$ will be given by

$$
y_{i}+P_{x} x_{i}=e r_{i}(s)
$$

The earnings, $e r$, equal to the social benefits, $s b$, in the case of an unemployed migrant and equal to the wages earned at the workplace in the case of an employed migrant: $w(x)$.

From (3) and (1) we obtain that the utility of a migrant is given by

$$
\begin{aligned}
& u_{i}(u n, s)=-v\left(I_{i}-x_{i}\right)+s b(s)-P_{x} x_{i} \quad \text { if unemployed } \\
& u_{i}(e m, s)=-v\left(I_{i}-x_{i}\right)+w\left(x_{i}, s\right)-P_{x} x_{i}-e \quad \text { if employed }
\end{aligned}
$$

A migrant chooses the optimal level of consumption of ethnic goods - social traits that maximize his utility $u$. The first order conditions of the unemployed and employed are given by:

$$
\begin{aligned}
& \frac{\partial u_{i}(\text { un })}{\partial x_{i}}=\frac{\partial v\left(I_{i}-x_{i}\right)}{\partial x_{i}}-P_{x}=0 \quad \text { if unemployed } \\
& \frac{\partial u_{i}(e m)}{\partial x_{i}}=\frac{\partial v\left(I_{i}-x_{i}\right)}{\partial x_{i}}+\frac{\partial w\left(x_{i}, s\right)}{\partial x_{i}}-P_{x}=0 \quad \text { if employed }
\end{aligned}
$$

We assume that the second order conditions are satisfied,

$$
-\frac{\partial^{2} v\left(I_{i}-x_{i}\right)}{\partial x_{i}^{2}}<0 \text { and }-\frac{\partial^{2} v\left(I_{i}-x_{i}\right)}{\partial x_{i}^{2}}+\frac{\partial^{2} w\left(x_{i}\right)}{\partial x_{i}^{2}}<0
$$

Denote by $x_{i}^{*}(u n, s)$ and $x_{i}^{*}(e m, s)$ the optimal level of consumption of ethnic

ethnicity and earnings. See Chiswick's (1978, 1991, 1998), Dustman (1997), McManus, Gould and Welch (1983), Trejo (1997), Berman, Lang and Siniver (2003) and Pendakur (2002) on language proficiency migrants and earnings. Culter and Gleaser (1997) and Borjas (2000) on segregation of minorities and earnings.

${ }^{13}$ One way of looking at this is that as one invests more time in consuming ethnic goods, he has less time for work. 
goods - as the social traits of the migrant for the unemployed and employed migrants, respectively, with a legality status of $s$.

From (5) it is clear that for the same ideal level $I_{i}$ the consumption of ethnic goods of the employed migrant will be lower than that of the unemployed. The reason for this is that the employed has additional cost to those of the unemployed for consuming the ethnic goods. This additional cost is the reduction in wages from consuming ethnic goods. Unemployed migrants obtain a fixed social benefit which is not a function of the level of consumption of ethnic goods. Thus,

(i) For any given ideal level $I_{i}$, the unemployed migrant consumes more ethnic goods (social trait) than the employed migrant: $x_{i}^{*}(u n, s)>x_{i}^{*}(e m, s)$.

Let us now consider the effect an increase in the ideal level has on the optimal consumption of ethic goods. It can be verified that $\frac{\partial x_{i}^{*}}{\partial I_{i}}=-\frac{\frac{\partial^{2} u_{i}}{\partial x_{i} \partial I_{i}}}{\frac{\partial^{2} u_{i}}{\partial x_{i}^{2}}}$. Since the second order conditions are satisfied, $\frac{\partial^{2} u_{i}}{\partial x_{i}^{2}}<0$, the sign of $\frac{\partial x_{i}^{*}}{\partial I_{i}}$ equals to the sign of $\frac{\partial^{2} u_{i}}{\partial x_{i} \partial I_{i}}$. $\frac{\partial^{2} u_{i}}{\partial x_{i} \partial I_{i}}$ equals (for both employed and unemployed migrants to $\frac{\partial^{2} v\left(I_{i}-x_{i}\right)}{\partial x_{i} \partial \partial_{x_{i}^{*}}}$. Since from

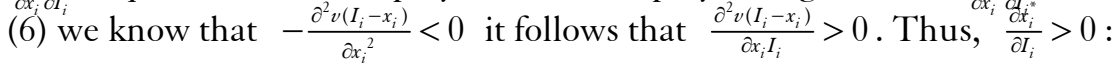

(ii) Increasing the ideal level $I_{i}$ increases the optimal choice of consumption of ethnic goods by the migrant.

Denote by $u_{i}^{*}(e m, s)$ and $u_{i}^{*}(u n, s)$ the optimal utility the employed and unemployed migrant with an illegality status of $s$ given their optimal consumption of social trait. Thus,

$$
\begin{aligned}
& u_{i}^{*}(u n, s)=-v\left(I_{i}-x_{i}^{*}(u n, s)\right)+s b(s)-P_{x} x_{i}^{*}(u n, s) \quad \text { if unemployed } \\
& u_{i}^{*}(e m, s)=-v\left(I_{i}-x_{i}^{*}(e m, s)\right)+w\left(x_{i}^{*}(e m, s)\right)-P_{x} x_{i}^{*}(e m, s)-e \quad \text { if employed }
\end{aligned}
$$

Let us now consider the case where an immigrant has to choose whether to be employed or unemployed. The migrant will choose to be employed if his utility from being employed is greater than his utility from being unemployed. Denote by $I^{*}$ the level of the ideal consumption of ethnic goods which will make an individual indifferent to whether he/she is employed or not. Namely, $I^{*}$ must satisfy the following equality:

$$
\begin{aligned}
& -v\left(I^{*}-x_{i}^{*}(u n, s)\right)+s b(s)-P_{x} x_{i}^{*}(u n, s)=-v\left(I^{*}-x_{i}^{*}(e m, s)\right) \\
& +w\left(x_{i}^{*}(e m, s)\right)-P_{x} x_{i}^{*}(e m, s)-e
\end{aligned}
$$


Remember from (i) that for any given ideal level $I, x_{i}^{*}(u n, s)>x_{i}^{*}(e m, s)$. Moreover, from the first order conditions of the employed and unemployed migrants (eq. (5)) it is clear that for any $I$. $I_{i}^{*}-x_{i}^{*}(u n, s)$ is constant, and for the employed migrant the higher the ideal level, the larger will be the difference between the ideal and actual level of consumption of ethnic goods(social traits): $\frac{\partial\left(I-x^{*}(e m)\right)}{\partial I}>0$. Therefore, we may conclude that,

(iii) Those migrants who have an ideal (satiation) preference lower than $I^{*}$ will choose to be employed and those with an ideal preference above $I^{*}$ will chose to be unemployed. ${ }^{14}$

[Figure 1]

\begin{tabular}{|lll|}
\hline & Unemployed & \\
\hline & $I^{*}$ & \\
\hline
\end{tabular}

The proportion of unemployed migrants would thus equal to $\int_{I^{*}}^{\bar{I}} f(I) d I=\int_{I^{*}}^{\bar{I}} \frac{1}{\bar{I}-\underline{I}} d I$.

It is clear from (8) that if we increase the unemployment benefits, $s b$, the ideal (satiation) preference, which will make the migrant indifferent to being employed or unemployed, will decrease. Moreover, if for every given $x$ the wage level of the employed decreases, the ideal level, $I$, which will make the migrants indifferent to being employed or unemployed, will decrease and more migrants will choice to be unemployed.

(iv) Increasing social benefits will increase the proportion of unemployed migrants.

(v) Decreasing the wages, which each employed migrant receives for a given level of consumption of ethnic goods, will increase the number of unemployed migrants.

\footnotetext{
${ }^{14}$ If we would assume that a high level of actual consumption of social traits provides the individual with recognition of the community status and, as Berman (2000) shows, it signals commitment to the community providing mutual insurance to those consuming high levels of social traits, we will find that the utility would have an extra component, which would be positively related to the individual consuming a social trait higher than the average. It is clear from the analysis presented above that if this utility is obtained from higher levels of consumption of ethnic goods, then only the individuals consuming lower levels of ethnic goods will be employed and those consuming high levels will be unemployed.
} 


\section{Legality Status of the Migrants}

Let us now consider how the legality status of the migrants affects the level of the ideal consumption of ethnic goods which will make an individual indifferent to whether he/she is employed or not. Denote this level by $I^{*}(s)(s=n, l)$.

There are two main differences between legal $(s=l)$ and illegal $(s=n)$ migrants:

(1) Unemployed legal migrants obtain higher social benefits from the host country while illegal migrants may not even obtain any. Unemployed illegal migrants may obtain assistance from the legal migrants and from family at the home country. Thus, it holds that $s b(l)>s b(n) \geq 0$.

(2) Legal immigrants earn, on average, higher wages than illegal migrants: Legal migrants pay taxes while illegal migrants do not pay taxes. The gross income of the legal migrants may or may not be higher than that of the illegal migrants. The net income of the legal migrants may be greater or lower than the illegal migrants. However, if the expected income is taken into consideration over the life span, the legal migrants income would be greater than that of the illegal migrant since the illegal migrant has a probability of being caught and deported. Thus, it holds that $w(l) \geq w(n)$.

We may conclude from results (iv) and (v) that

(vi) If both the illegal and legal migrants earn the same wages, then $I^{*}(n)>I^{*}(l)$. Thus, the unemployment level of the illegal migrants will be lower than that of the legal migrants.

(vii) Since $w(l) \geq w(n)$, then if the unemployment benefits the illegal migrant obtains are zero or very close to zero $s b(n)=0$, then $I^{*}(n)>I^{*}(l)$. Thus, the unemployment level of the illegal migrants will be lower than that of the legal migrants.

From (i), (vi) and (vii) we obtain that

(viii) If the wages the legal and illegal migrants' earn are identical, on average, the illegal migrants will consume less ethnic goods than the legal migrants.

\section{Expected Consumption of Ethnic Goods}

Let us now calculate the expected amount of consumption of ethnic goods by both the employed and unemployed migrants. Denote by $E\left[X^{*}\right]$ the expected amount of consumption of ethnic goods by all the migrants together.

$$
\begin{aligned}
E\left[X^{*}\right]= & \int_{\underline{I}}^{I^{*}(l)} x_{i}^{*}(e m, l) \frac{1}{\bar{I}-\underline{I}} d I+\int_{I^{*}(l)}^{\bar{I}} x_{i}^{*}(u n, l) \frac{1}{\bar{I}-\underline{I}} d I \\
& +\int_{\underline{I}}^{I^{*}(n)} x_{i}^{*}(e m, n) \frac{1}{\bar{I}-\underline{I}} d I+\int_{I^{*}(n)}^{\bar{I}} x_{i}^{*}(u n, n) \frac{1}{\bar{I}-\underline{I}} d I
\end{aligned}
$$


It is clear that as the social benefits increase (both for the legal and illegal migrants), more migrants will be unemployed, and since the unemployed consume more ethnic goods than the employed migrants, increasing the social benefits will increase the expected (average level of) consumption of ethnic goods: $\frac{\partial E\left[X^{*}\right]}{\partial s b}>0$.

\section{Wages, consumption of ethnic goods, and the expected consumption of ethnic goods}

We assume that migrants and the local population are not identical. As long as the migrants hold on to their ethnicity, the local population will not recognize them as full substitutes to the local population and the local workers will not always be willing to cooperate entirely with them. Using the examples presented in the appendix, if a Moslem migrant prays five times a day, this may well disturb his interaction with the local workers, and, as such, the local workers may not want to work enthusiastically with him. If a migrant Jew will only eat kosher food, this may limit the places the workers can go to a "working lunch," which may affect productivity and the willingness of the local population to work with the migrants, etc. In other words, migrants that hold on to their ethnicity may affect their productivity via their interaction with the local population. As a result of the consumption of these ethnic goods the level of efficiency of the migrants decreases. The decline in productivity and efficiency can result from such hostile activities by the local population as harassing the members of the migration group, not cooperating with them, discriminating against them, and so on. Such activities decrease the migrants' productivity, and thus their efficiency. ${ }^{15} 1617$

Let us now discuss the migrant's wages $w$. The wages are determined by the actions taken by the migrants, and the general attitude of the population to the migrants. This attitude is reflected in the average level of consumption of ethnic goods, $E\left[X^{*}\right]$, which is a function of the consumption of social traits of both the employed and unemployed migrants. The more ethnic goods the migrants consume, the more they distinguish themselves from the local population. This will decrease

\footnotetext{
15 This is similar to the cooperation and harassment activities described in insider-outsider theory (Lindbeck and Snower, 1998).

${ }^{16}$ Assimilation is not always beneficial for the minority; see Epstein (2003) for a discussion of migrant assimilation. For now, we ignore such possibilities, but we will return to them later in this paper.

${ }_{17}$ Another reason for the difference in the levels of efficiency between migrants and the local population can be seen in Kahanec (2006). He shows that in a world where heterogeneous skills are available in skill-specific social networks these efficiency differentials systematically expose minority and majority peoples to different incentives that concern skill choice, and depending on the equilibrium organization of skill acquisition, make them acquire different (combinations of) skills. An important consequence of such differentiation is that wages per efficiency unit of minority and majority labor typically differ since these are no longer perfect substitutes.
} 
the willingness of the local population to work with them, and will increase the "harassment" activities of the local population. It is therefore assumed that the wages are a function both of the consumption of the ethnic goods of the unemployed and employed migrants and the individual level chosen by the employed migrant, $x_{i}^{*}: w_{i}\left(E\left[X^{*}\right], x_{i}^{*}\right)$ such that ${ }^{18}$

$$
\frac{\partial w_{i}\left(E\left[X^{*}\right], x_{i}^{*}\right)}{\partial E\left[X^{*}\right]}<0 \text { and } \frac{\partial w_{i}\left(E\left[X^{*}\right], x_{i}^{*}\right)}{\partial x_{i}^{*}}<0
$$

As we have shown above, the consumption of ethnic goods is a function of different parameters. In particular, it is a function of the unemployment benefits $s b$ : $w_{i}=w_{i}\left(E\left[X^{*}(s b)\right], x_{i}^{*}(s b)\right)$.

Increasing unemployment benefits will thus have two direct effects: First, the consumption of ethnic goods for those migrants, who are employed but decide to become unemployed, will increase, and secondly, the consumption of ethnic goods will not change for those migrants who decide to remain employed. On the whole, the expected consumption of ethnic goods will increase and as a result wages will decrease:

$$
\begin{aligned}
\frac{\partial w_{i}}{\partial s b}= & \frac{\partial w_{i}\left(E\left[X^{*}(s b)\right], x_{i}^{*}(s b)\right)}{\partial E\left[X^{*}(s b)\right]} \frac{\partial E\left[X^{*}(s b)\right]}{\partial s b} \\
& +\frac{\partial w_{i}\left(E\left[X^{*}(s b)\right], x_{i}^{*}(s b)\right)}{\partial x_{i}^{*}(s b)} \frac{\partial x_{i}^{*}(s b)}{\partial s b}<0
\end{aligned}
$$

Increasing the social benefits, $s b$, will increase the unemployment level and the consumption of ethnic goods. Since wages will now decrease, some employed migrants will choose to become unemployed, and thus the consumption of ethnic goods will increase, which will again decrease wages. ${ }^{19}$

\footnotetext{
${ }^{18}$ In terms of the production function described in the appendix we may write $d$ as a function of wages and unemployment benefits. $d_{i}()=.d\left(E\left[X^{*}\left(w_{i F}, s b\right), x_{i}^{*}\left(w_{i F}, s b\right)\right]\right)$.

${ }^{19}$ Using the analysis presented in the appendix: assume that the wages of the local population are fixed at a level of $w_{L}$, thus using the analysis presented in the appendix $d\left(E\left(\left[X^{*}\left(w_{F}, s b\right)\right]\right) w_{L}=w_{F}\right.$. Since $\frac{d d\left(E\left[X^{*}\right]\right)}{d w_{F}}=\frac{\partial d\left(E\left[X^{*}\right]\right)}{\partial E\left[X^{*}\right]} \frac{\partial E\left[X^{*}\right]}{\partial w_{F}}>0$. Assuming that the wages are greater than one. $\frac{\partial d\left(E\left[X^{*}\left(w_{F}, s b\right)\right]\right)}{\partial E\left[X^{*}\right]} \frac{\partial E\left[X^{*}\left(w_{F}, b b\right)\right]}{\partial w_{F}} w_{L}=1$. Namely, $\quad \frac{\partial d\left(E\left[X^{*}\left(w_{F}, 5 b\right)\right]\right.}{\partial E\left[X^{*}\right]} \frac{\partial E\left[X^{*}\left(w_{F}, s b\right)\right]}{\partial w_{F}}=\frac{1}{w_{L}} \quad$ thus, $\quad 0<\frac{d d\left(E\left[X^{*}\right]\right)}{d w_{F}}<1 . \quad$ The solution of $d\left(E\left[X^{*}\left(w_{F}, s b\right)\right]\right) w_{L}=w_{F}$ would be in a diagram with $w_{F}$ on one axis and $d w_{L}$ on the other we would get that the $45^{0}$ line intercepts with the function $d w_{L}$ at the equilibrium wage of the migrations.
} 
Increasing the social benefits of the unemployed will increase the consumption of ethnic goods and decrease wages. Decreasing the wages of the migrants will decrease the number of the employed, and increase again the consumption of ethnic goods. Thus,

(ix) Increasing the social benefits of the unemployed will increase consumption of ethnic goods decreasing employment and wages.

\section{Illegality of the Migrants}

As presented above, if the legal and illegal migrants earn similar wages while the illegal migrants do not earn social benefits and the legal do, the illegal workers will consume less ethnic goods than the legal. This argument may also hold in the case where the illegal workers earn less than the legal workers. Since the consumption of ethnic goods is costly, decreasing earnings will also decrease the consumption of ethnic goods. Thus, there would be thus two opposite effects: as income decreases, the consumption of ethnic goods also decreases, while/maybe start a new sentence here with "on the other hand" a decrease in income decreases the opportunity of purchasing, and thus also decreasing the consumption of ethnic goods Thus there exists a situation under which the illegal migrants will consume more ethnic goods than the legal migrants.

We can conclude that

(x) there exis/ conditions under which increasing the illegal migration population will:

a. decrease the expected consumption of ethnic goods,

b. increase the wages of the legal migration

c. decrease the consumption of ethnic good by the legal migrants

d. increase assimilation.

This last result states that increasing the number of illegal migrants may well increase the assimilation of the legal migrants. In order for this to happen the wages of the illegal migrants should not be too low, and the illegal migrants should not gain from social benefits, if unemployed.

If there is a quota for the number of migrants, then the optimal strategy would be to divide it between legal and illegal migrants. With time, the number of illegal migrants can decrease while the number of legal migrants increases.

In a dynamic setting, when permitting migration, there should be both legal and illegal migration. Over time the number of illegals should decrease while increasing the number of legals. This is true since the illegal migrants will allow the assimilation of the legal migrants, and new legal migrants entering will be assimilated easier since the expected consumption of ethnic goods will be lower as a result of the assimilation of the former migrants. 
We conclude from this that illegal migrants may well play a positive role in the assimilation of migrants into the host country.

\section{Concluding Remarks}

We developed a model that deals with the relationship between the welfare state, the choice of social traits, the consumption of ethnic goods, the employment of migrants, and their legal status. We begin by showing that wages earned by the migrants depend on their assimilation level. We then continue to look at the choice of the migrants with regard to the consumption of ethnic goods. This consumption makes the migrants differ from the local population, and as a result affects their wages. We show that if wages are a function of the level of consumption of ethnic goods, then those migrants, who have low ideal preferences for consumption of these items, will tend to be employed while the others remain unemployed. The average level of consumption of ethnic goods of the employed will be lower than that of the unemployed.

Illegal migrants may well choose to consume less ethnic goods than the legal migrants. As a result, this will affect the expected average level of consumption of ethnic goods by the migrants and affect the willingness of the local population to accept then.

In our model, migrants have to choose their level of social traits and consumption of ethnic goods. Each migrant has his/her own ideal traits, and given the average level in the society, chooses his consumption level. As the consumption increases, the migrants differ from the local population, and assimilate less. Less assimilation affects the reaction of the local population towards the migrants and their willingness to accept them. This affects wages and unemployment, and thus social benefits affect the level of the migrant's chosen social traits. Therefore, countries providing high welfare benefits create a trap in which the migrants who receive these benefits consume a larger amount of ethnic goods, thus decreasing the willingness of the local population to accept them into the economy. This unwillingness of the local population to accept them increases their probability of being dependant on the welfare state. ${ }^{20}{ }^{21}$ On the other hand, illegal migrants may well play an important role in the assimilation of the legal migrants. The employed

\footnotetext{
${ }^{20}$ In the USA in 1996 it was determined that migrants, less than three years in the country, will not receive food stamps. This would increase the consumption of ethnic goods by the unemployed and decrease the probability of being unemployed.

${ }^{21}$ The results presented also add to the blossoming literature on the majority - minority conflict and its resolution, assimilation, and the reestablishment of cultural identity (see, for example, Gradstein and Justman, 2005, Anas, 2002, Bisin and Verdier, 2000, Dustmann, Fabbri and Preston, 2004, and Lazear, 1999).
} 
illegal migrants decrease the average consumption of ethnic goods which increases the willingness of the local population to accept the migrants. This increases the migrants' wages and willingness to work, and decreases the dependency of the legal migrants on the welfare state. 


\section{References}

Akerlof, George A., and Rachel E. Kranton (2000), "Economics and Identity," Quarterly Journal of Economics, 115, pp.715-753.

Anas, A. (2002), "Prejudice, Exclusion and Compensating Transfers: The Economics of Ethnic Segregation,” Journal of Urban Economics, 52 (3), pp.409-32.

Bisin, A. and T. Verdier (2000), "Beyond the Melting Pot," Cultural Transmission, Marriage, and the Evolution of Ethnic and Religious Traits, Quarterly Journal of Economics, August, pp.955-988.

Bauer, T., G. S. Epstein and I. N. Gang (2007) "The Influence of Stocks and Flows on Migrants' Locational Choices," Resurrect in Labor Economic, 26, pp.199-229.

Bauer, T., M. Lofstrom and K. F. Zimmermann (2000), "Immigration Policy, Assimilation of Immigrants and Natives' Sentiments Towards Immigrants: Evidence from 12 OECD Countries," Swedish Economic Policy Review, 7, pp.11-53.

Berman E. (2000), "Sect, Subsidy and Sacrifice: An Economist's View of Ultra-Orthodox Jews," Quarterly Journal of Economics, 115(3), pp.905-953(49).

Berman, E., K. Lang and E. Siniver (2003), "Language-Skill Complementarily: Returns to Immigrant Language Acquisition,” Labour Economics, 10, pp.265-290.

Boeri, T., G. Hanson and B. McCormick (2002), Immigration Policy and the Welfare System, Oxford, Oxford University Press.

Borjas, G. J. (2000): “Ethnic Enclaves and Assimilation," Swedish Economic Policy Review, 7, pp.89-122.

Brekke K. A., K. Snorre and N. Karine (2003), "An Economic Model of Moral Motivation," Journal of Public Economics, 87 (9), pp.1967-1983(17).

Chiswick, B. R. (1978), “The Effect of Americanization on the Earnings of Foreign-Born Men,” Journal of Political Economy, 86 (5), pp.897-922.

(1991), "Speaking, Reading, and Earning among Low-skilled Immigrants," Journal of Labor Economics, Vol. 9, No. 2, pp.149-170.

(1998), "Hebrew Language Usage: Determinants and Effects among Immigrants in Israel," Journal of Population Economics, 11, pp.253-71.

Chiswick, Carmel U. (2009), “The Economic Determinants of Ethnic Assimilation.” Journal of Population Economics, 22(4), pp.859-880.

Constant, A. and K. F. Zimmermann (2005), "Immigrant Performance and Selective Immigration Policy: A European Perspective" National Institute Economic Review, 194, pp.94-105.

Constant, A., L. Gataullina and K. F. Zimmermann (2009), "Ethnosizing Immigrants," Journal of Economic Behavior and Organization, 69(3), pp.274-287.

Culter, D. M and E. L. Gleaser (1997), “Are Ghettos Good or Bad?,” Quarterly Journal of Economics, 112(3), pp.827-872.

Dustmann, C. (1997), "The Effects of Education, Parental Background and Ethnic Concentration on Language," The Quarterly Review of Economics and Finance, Vol. 37, pp.245-262. 
Dustmann, C., F. Fabbri, and I. Preston (2004), "Ethnic Concentration, Prejudice and Racial Harassment of Minorities, Manuscript," University College, London.

Epstein, G. S. (2003), "Labor Market Interactions Between Legal and Illegal Minorities," Review of Development Economics, 7(1), 2003, pp.30-43.

(2007), "Extremism Within the Families," Journal of Population Economics, 20, pp.707-715.

(2009) “Willingness to Assimilate and Ethnicity," Nordic Journal of Political Economy, 35, pp.1-12.

(2010), "Informational Cascades and the Decision to Migrate," in Gil S. Epstein, and Ira N. Gang (Eds), Migration and Culture, Frontiers of Economics and Globalization, Volume 8, Emerald Group Publishing Limited.

Epstein, G. S. and A. L. Hillman (2003), "Unemployed Immigrants and Voter Sentiment in the Welfare State," Journal of Public Economics, pp.1641-1655.

Epstein G. S. and I. N. Gang (2006), "Ethnic Networks and International Trade," in Labor Mobility and the World Economy, Federico Foders and Rolf J. Langhammer (ed), Springer (Berlin, Heidelberg), pp.85-103.

(2010) "Migration and Culture" in Gil S. Epstein, and Ira N. Gang, (Eds), Frontiers of Economics and Globalization, Volume 8, Migration and Culture, Emerald Group Publishing Limited.

Erickson, J. A. (1992), "Adolescent Religious Development and Commitment: A Structural Equation Model of the Role of Family, Peer Group, and Educational Influences," Journal of the Scientific Studies of Religion, XXXI, pp.131-152.

Gang, I. N. and Rivera-Batiz, F. (1994), "Labor Market Effects of Immigration in the United States and Europe: Substitution vs. Complementarity," Journal of Population Economics, 7, pp.157-175.

Gradstein, M. and M. Justman (2005), “The Melting Pot and School Choice, manuscript," Journal of Public Economics, 89, pp.871-896.

Hays, B. C. and Pittelkow Yvonne, (1993), "Religioun Belifs, Transmission and the Family: An Australian Study," Journal of Marriage and the Family, LV, pp.755-766.

Kahanec, M. (2006), "Ethnic Specialization and Earnings Inequality: Why Being a Minority Hurts but Being a Big Minority Hurts More,” IZA DP number 2050.

Lazear, E. P. (1999), “Culture and Language,” Journal of Political Economy, 107 (6, pt. 2), S95-S126.

Lindbeck, A. and D. J. Snower (1988), "Cooperation, Harassment, and Involuntary Unemployment, An Insider-Outsider Approach,” American Economic Review, 78(1) pp.167-188.

McManus, W. S., W. Gould, and F. Welch (1983), "Earning of Hispanic Men: The Role of English Language Proficiency,” Journal of Labor Economics, 1, pp.101-130.

Pendakur, K. and R. Pendakur (2002), "Language as both Human Capital and Ethnicity," The International Migration Review, 36, pp.147-177.

Schultz-Nielsen, M. L. and A. Constant (2004), "Employment Trends for Immigrants and Natives" in: T. Tranaes and K. F. Zimmermann Migrants, Work, and the Welfare State, Odense, University Press of Southern Denmark, pp.119-146. 
Shapiro, C. and J. Stiglitz (1984), "Equilibrium Unemployment as a Worker Discipline Device," American Economic Review, 74, pp.433-44.

Tranaes, T. and K. F. Zimmermann (2004), "Migrants, Work, and the Welfare State: An Introduction," in: T. Tranaes and K. F. Zimmermann Migrants.

Venturini, A. (2004), Post-War Migration in Southern Europe. An Economic Approach, Cambridge, Cambridge University Press.

Wildasin, D. (2004), "Economic integration and the welfare state, in Social Union, Migration and the Constitution: Integration at Risk," CES-ifo Forum, Autumn Vol. 5, No. 3, pp.19-26. 


\section{Appendix: Production and wages}

Consider a firm that has two factors of production: local workers, $L_{L}$, and migrants, $L_{M}$. For simplicity, we assume that there is only one group of migrants. We assume that migrants and the local population are not identical. As long as the migrants hold on to their ethnicity, the local population will not recognize them as fully substitutes to the local population and the local workers will not always be willing to cooperate fully with them. As presented in the paper, if a Moslem migrant prays five times a day, this may well disturb his interaction with the local workers and, as such, the local worker may not want to work enthusiastically with him. If a migrant Jew will only eat kosher food, this may limit the places the workers can go to a "working lunch" and may affect productivity and the willingness of the local population to work with the migrants, etc. In other words, migrants, that hold on to their ethnicity, may affect there productivity via their interaction with the local population.

We normalize the efficiency level of local workers to unity and the migrants' productive/efficiency level to equal $d(.) . d($.$) plays an important role in the$ determination of production and wages; aside from these, labor is homogeneous.

$d($.), the migrants' productive/efficiency level $(0<d()<1$.$) , is a function of the$ level of consumption of ethnic goods. As a result of the consumption of these goods the level of efficiency of the migrants decrease, as stated above this can be a result of different activities by the local population such as harassing the members of the migration group, not cooperating with them, discriminating against them, and so on. Such activities decrease the migrants' productivity and thus their efficiency. ${ }^{22}$ $d($.$) reflects the productivity and efficiency of the migrants, relative to the local$ population. The representative firm's production function is given by

$$
Q_{t}(L)=f\left(L_{L}+d(.) L_{M}\right)
$$

such that

$$
\frac{\partial f(L)}{\partial L}>0 \quad \text { and } \quad \frac{\partial^{2} f(L)}{\partial L^{2}}<0
$$

Let $w_{L}$ be the local worker's wage, and $w_{F}$ be the migrant's wage. We assume that the wages the local population and the migrants receive equals their marginal product values. We could assume that the local population has market power over their employers; this would not change our results.

Normalizing the price of the product to unity, the profits of the firm are given by

${ }^{22}$ Similar to the harassment activities in the insider-outsider theory (see, Lindbeck and Snower, 1998). 


$$
\pi(.)=f\left(L_{L}+d(.) L_{M}\right)-\left(w_{L} L_{L}+w_{F} L_{M}\right) .
$$

The first order conditions for maximization are

$$
\frac{\partial \pi(.)}{\partial L_{L}}=f^{\prime}-w_{L}=0 \Rightarrow f^{\prime}=w_{L}
$$

and,

$$
\frac{\partial \pi(.)}{\partial L_{M}}=d(.) f^{\prime}-w_{F}=0 \Rightarrow d(.) f^{\prime}=w_{F} .
$$

Equation (A3) represents the wage conditions for the local population workers and (A4) represents the wage conditions for the migrants, since $0<d()<$.1 the wages the migrants earn are lower than that of the local population. The ratio of the wages: $\frac{w_{F}}{w_{L}}$ equals to $d($.$) . We now wish to discuss what determines d($.$) . Let us$ look at the determinacy of $d($.) which, as we discussed above, is a function of the consumption of ethnic goods by the migrants. The consumption of ethnic goods is by both employed and unemployed migrants and will have an effect on the productivity of the migrants via the willingness of the local population to work, cooperate and coordinate production with the migrants. 